Int. J. Plant Sci. 173(8):885-893. 2012.

(C) 2012 by The University of Chicago. All rights reserved.

1058-5893/2012/17308-0004\$15.00 DOI: $10.1086 / 667231$

\title{
MORPH RATIO VARIATION AND SEX ORGAN RECIPROCITY IN STYLE-DIMORPHIC NARCISSUS ASSOANUS
}

\author{
John D. Thompson, ${ }^{1, *}$ Adeline C. Cesaro, ${ }^{*}$ and Juan Arroyo† \\ *Unité Mixte de Recherche 5175, Centre d'Ecologie Fonctionnelle et Evolutive, Centre National de la Recherche Scientifique, \\ 1919 Route de Mende, 34293 Montpellier Cedex 5, France; and tDepartamento de Biología Vegetal y Ecología, \\ Universidad de Sevilla, Apartado 1095, 41080-Sevilla, Spain
}

\begin{abstract}
The maintenance of floral polymorphisms depends on rates and efficiency of cross-pollination within and among mating types in relation to their relative frequency. Here, we examine whether stigma-anther reciprocity in style-dimorphic Narcissus assoanus (populations show either 1:1 ratios of long-styled [L-morph] and short-styled [S-morph] plants or significantly L-morph-biased ratios) is correlated with morph ratio variation and whether such differences affect female fitness. In a natural population we created experimental plots of S-morph maternal plants and quantified their female fertility in the presence of either L-morph donors or S-morph donors with only their lower anther levels (we emasculated upper-level anthers). We also quantified floral traits and reciprocity in the positions of stigmas and anthers in 30 natural populations across the species' geographic distribution. We found an increase in seed set on maternal S-morph plants in the presence of L-morph donors and patterns of trait variation that may contribute to enhanced reciprocity with increasing frequency of the S-morph. Subtle differences in the position of sex organs affect pollen transfer and are correlated with morph ratio variation, indicative of frequency-dependent selection.
\end{abstract}

Keywords: floral polymorphism, floral trait variation, morph ratio, Mediterranean.

\section{Introduction}

In flowering plants, negative frequency-dependent selection contributes to the maintenance of sexual polymorphisms in which cross compatible mating types benefit reproductively from the presence of one another. Here, the fitness of a given morph will depend on the frequencies of other morphs in a population; each morph is fitter than the other when rare but not when common (Fisher 1930). The evolution and maintenance of sexual polymorphism in flowering plants thus depends on the rates and efficiency of cross-pollination among mating types. Evidence for such frequency-dependent mating success and thus selection has been reported in several case studies of correlated variation between morph ratios and (i) fitness in natural populations (Gigord et al. 2001; Thompson et al. 2003; Hodgins and Barrett 2006), (ii) fitness in artificial populations (McCauley and Brock 1998; PérezBarrales and Arroyo 2010), (iii) temporal variation in morph ratios (Curtis and Curtis 1985; Eckert et al. 1996), or (iv) variation in flower size and floral organ positions (Barrett et al. 2004; Hodgins and Barrett 2008b).

Species with a style polymorphism but that do not show associated dimorphic variation in anther height, i.e., are not distylous (fig. 1), provide useful systems in which to study morph-specific patterns of mating (Lloyd and Webb 1992a, $1992 b$; Barrett et al. 1996). In species that show such a

${ }^{1}$ Author for correspondence; e-mail: john.thompson@cefe.cnrs.fr. Manuscript received February 2012; revised manuscript received May 2012. stigma-height dimorphism, there is no evidence for associated heteromorphic incompatibility common to most distylous species; cross-pollinations among individuals of the same morph are as fertile as crosses among morphs. A consequence of this is that morph ratios can vary greatly if assortative mating exceeds disassortative mating. An implicit assumption that is made here is that the long-styled morph (L-morph) is homozygous recessive and the short-styled morph (S-morph) heterozygous for alleles affecting style length.

A key issue here concerns the relative rates of within- and between-morph mating and how these rates may be governed by the relative reciprocity of male and female organs in the different morphs. The genus Narcissus contains several species with a stigma-height dimorphism that also have population morph ratios that deviate significantly from $1: 1$, often with striking geographic patterns of variation (Arroyo et al. 2002; Barrett et al. 2004; Thompson 2005). These situations set the scene for the investigation of how such morph ratio variation may reflect variation in floral morphology and/or pollinator assemblages. In two species it has been shown that morph ratio variation may arise when the identity of pollinators varies among populations or regions as a result of differential pollination of the two morphs (Arroyo and Dafni 1995; Pérez-Barrales and Arroyo 2010).

In Narcissus assoanus, morph ratios commonly take the form of either a significant bias in favor of the L-morph or a nonsignificant deviation from a 1:1 morph ratio (Baker et al. 2000b; Thompson 2005). No monomorphic populations are known, despite investigations across the full geo- 


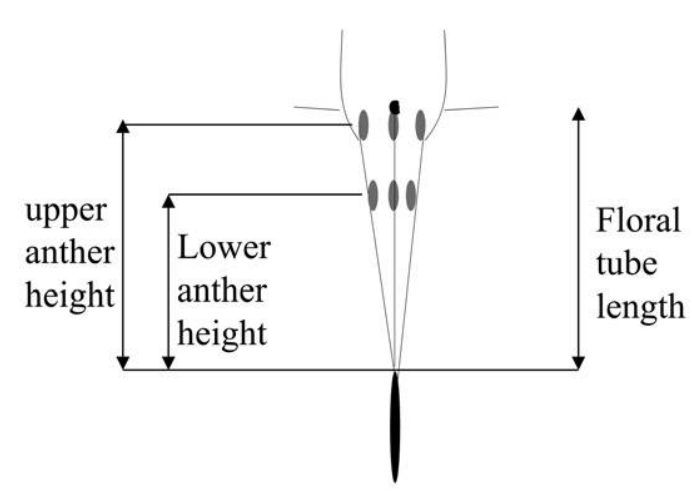

L-morph

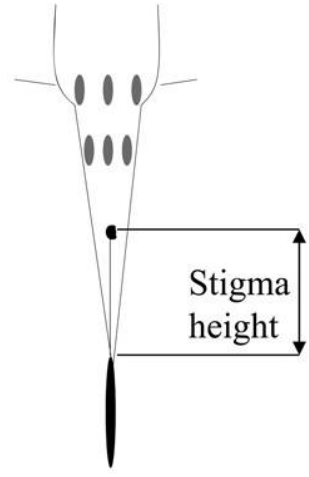

S-morph

Fig. 1 Schematic representation of the relative position of stigmas and anthers in L-morph and S-morph flowers of Narcissus assoanus and the flower measurements made in this study.

graphic range of this species ( $\sim 200$ populations; J. D. Thompson, unpublished observations). This variation in morph ratio is known to create conditions for frequencydependent selection that favors the S-morph when it is rare (Thompson et al. 2003). Like other Narcissus, N. assoanus flowers have two anther levels inside the corolla tube (fig. 1). In this species and others (Baker et al. 2000b; Pérez-Barrrales et al. 2006; Pérez-Barrales and Arroyo 2010) the upper-level anthers of the two morphs are at the same height as each other and as the stigma of the L-morph, while lower anthers are positioned lower in the flower of the L-morph than in the S-morph. Selection to reduce the height of the lower anthers in the L-morph may increase male fertility because of more proficient pollen dispersal to stigmas of the S-morph. In contrast, selection to increase the height of lower-level stamens in the S-morph may reduce self-pollination and self-interference (Cesaro et al. 2004). Two predictions can be made here. The first is that, assuming that pollen transfer is more efficient when pollen donor level and pollen recipient level are closer to each other, one would predict pollen transfer from lower L-morph anthers to S-morph stigmas to be more efficient than from S-morph lower anthers to S-morph stigmas (of different plants). Second, the frequency of the S-morph in a population should cause selection on lower anther position in the L-morph. As a result, the difference between lower anther position in the L-morph and stigma position in the S-morph should be negatively correlated with the proportion of $S$-morph plants in a population.

In this study, we test these two predictions by addressing two principal questions. First, does the lower anther position of the L-morph facilitate pollination of the S-morph? To examine this question, we created experimental plots in a natural population with L-morph and S-morph pollen donors and assessed the male fertility of their lower anthers for the pollination of S-morph recipient plants. Second, is there a correlation between morph ratio variation and anther height in the two morphs? Here, we examined variation in sex organ position among 30 populations across the range of $N$. assoanus in the western Mediterranean region to assess whether the distance between the stigma in the S-morph and lower an- thers of the L-morph varies in relation to the frequency of the S-morph.

\section{Material and Methods}

\section{Pollen Transfer Efficiency}

To assess the relative rates of pollen transfer from lowerlevel anthers of the L-morph and S-morph to the stigma of the S-morph, we carried out an experimental study in a natural population in southern France (called Ceyrac close to Sauve; lat. $43^{\circ} 55^{\prime} 240^{\prime \prime} \mathrm{N}$, long. $\left.003^{\circ} 53^{\prime} 400^{\prime \prime} \mathrm{E}\right)$. We chose to work at this site because the morph ratio is not significantly different from $1: 1$; the lower anthers of the L-morph are significantly lower in the floral tube than are those of the Smorph, high densities of naturally flowering plants occur over a wide area at this site, and the presence of abundant pollinators makes experimental work feasible at this site (see Thompson et al. 2003).

On March 16, 2002, as flowering began at the site, we randomly set out 13 replicate plots of each of two treatments in areas where large numbers of flower buds were emerging. Each plot was roughly $1 \mathrm{~m}^{2}$ in area and was surrounded by a border at least $1 \mathrm{~m}$ wide in which we removed all flowers buds of Narcissus assoanus during the course of the experiment. As a result there were no flowering plants in this border. During observations of similar experiments at this site, we have observed that creating a border around plots with no flowers causes pollinators to visit several or many flowers before leaving the plot and not to move repeatedly in and out of the plot. Each pollinator entering a plot thus tends to visit several flowers. As suggested by results from previous work at this site (Thompson et al. 2003), we thus assume that pollen delivery to stigmas from outside the plots is not significant enough to mask any effects related to differential pollen transfer in our experimental plots. What is important here is that the frequency of L-morph and S-morph plants in the studied population, and thus around the experimental 
Table 1

Morph Ratio and G-Test for Significant L-Morph Bias in Each of 30 Populations of Narcissus assoanus in Spain (Groups 1 and 2) and Southern France (Groups 3-5)

\begin{tabular}{|c|c|c|c|c|c|}
\hline Group/population & Elevation $(\mathrm{m})$ & Coordinates (lat., long.) & Morph ratio & $G$-test & Sample size \\
\hline 1/1 Algarinejo & 858 & $37^{\circ} 19^{\prime} 168^{\prime \prime} \mathrm{N}, 4^{\circ} 08^{\prime} 086^{\prime \prime} \mathrm{W}$ & 6.04 & $57.64 *$ & 100 \\
\hline 1/2 Alicante & 595 & $38^{\circ} 41^{\prime} 129^{\prime \prime} \mathrm{N}, 0^{\circ} 03^{\prime} 208^{\prime \prime} \mathrm{W}$ & 1.49 & $4.03 *$ & 100 \\
\hline 1/3 Cabra & 1159 & $37^{\circ} 29^{\prime} 438^{\prime \prime} \mathrm{N}, 4^{\circ} 22^{\prime} 888^{\prime \prime} \mathrm{W}$ & 3.23 & $28.41^{*}$ & 100 \\
\hline 1/4 Grazalema & 1000 & $36^{\circ} 46^{\prime} 638^{\prime \prime} \mathrm{N}, 5^{\circ} 25^{\prime} 655^{\prime \prime} \mathrm{W}$ & 1.69 & $6.84 *$ & 100 \\
\hline 1/5 La Muela & 849 & $37^{\circ} 29^{\prime} 438^{\prime \prime} \mathrm{N}, 4^{\circ} 22^{\prime} 888^{\prime \prime} \mathrm{W}$ & 4.30 & $41.38 *$ & 100 \\
\hline 1/6 Zahara de la Sierra & 1009 & $36^{\circ} 45^{\prime} 786^{\prime \prime} \mathrm{N}, 5^{\circ} 22^{\prime} 570^{\prime \prime} \mathrm{W}$ & 1.61 & $5.82 *$ & 100 \\
\hline 2/1 Banaguás & 740 & $42^{\circ} 34^{\prime} 062^{\prime \prime} \mathrm{N}, 0^{\circ} 34^{\prime} 367^{\prime \prime} \mathrm{W}$ & 1.74 & $7.95 *$ & 100 \\
\hline 2/2 Banaguás 2 & 755 & $42^{\circ} 34^{\prime} 062^{\prime \prime} \mathrm{N}, 0^{\circ} 34^{\prime} 367^{\prime \prime} \mathrm{W}$ & 2.71 & $21.98 *$ & 100 \\
\hline 2/3 Monte Perdido & 1061 & $42^{\circ} 36^{\prime} 521^{\prime \prime} \mathrm{N}, 0^{\circ} 07^{\prime} 250^{\prime \prime} \mathrm{W}$ & 2.17 & $13.26^{*}$ & 100 \\
\hline 2/4 Navasa & 926 & $42^{\circ} 32^{\prime} 272^{\prime \prime} \mathrm{N}, 0^{\circ} 28^{\prime} 383^{\prime \prime} \mathrm{W}$ & 3.44 & $30.77^{*}$ & 100 \\
\hline 2/5 Rapun & 874 & $42^{\circ} 29^{\prime} 353^{\prime \prime} \mathrm{N}, 0^{\circ} 23^{\prime} 121^{\prime \prime} \mathrm{W}$ & 1.71 & $6.84 *$ & 100 \\
\hline 2/6 San Juan de la Peña & 1278 & $42^{\circ} 30^{\prime} 169^{\prime \prime} \mathrm{N}, 0^{\circ} 40^{\prime} 403^{\prime \prime} \mathrm{W}$ & 3.02 & $26.16 *$ & 100 \\
\hline 3/1 Lauret & 175 & $43^{\circ} 50^{\prime} 126^{\prime \prime} \mathrm{N}, 3^{\circ} 53^{\prime} 674^{\prime \prime} \mathrm{E}$ & 1.91 & $8.52 *$ & 87 \\
\hline 3/2 Les Cognets & 250 & $43^{\circ} 52^{\prime} 336^{\prime \prime} \mathrm{N}, 3^{\circ} 51^{\prime} 675^{\prime \prime} \mathrm{E}$ & 2.43 & $30.95 \%$ & 146 \\
\hline 3/3 Mas Rigaud & 170 & $43^{\circ} 47^{\prime} 293^{\prime \prime} \mathrm{N}, 3^{\circ} 50^{\prime} 074^{\prime \prime} \mathrm{E}$ & 2.27 & $9.27 *$ & 112 \\
\hline 3/4 St-Bauzille-de-Montmel & 250 & $43^{\circ} 46^{\prime} 607^{\prime \prime} \mathrm{N}, 3^{\circ} 56^{\prime} 904^{\prime \prime} \mathrm{E}$ & 6.38 & $115.0 *$ & 193 \\
\hline 3/5 St-Mathieu-de-Tréviers & 110 & $43^{\circ} 46^{\prime} 496^{\prime \prime} \mathrm{N}, 3^{\circ} 52^{\prime} 300^{\prime \prime} \mathrm{E}$ & 1.80 & $11.60 \%$ & 133 \\
\hline 3/6 Valflaunes (Col Hortus) & 325 & $43^{\circ} 49^{\prime} 090^{\prime \prime} \mathrm{N}, 3^{\circ} 51^{\prime} 200^{\prime \prime} \mathrm{E}$ & 2.06 & $28.77^{*}$ & 130 \\
\hline 4/1 Arboras & 270 & $43^{\circ} 42^{\prime} 509^{\prime \prime} \mathrm{N}, 3^{\circ} 29^{\prime} 805^{\prime \prime} \mathrm{E}$ & 1.00 & $0^{\mathrm{ns}}$ & 172 \\
\hline 4/2 Cabane & 180 & $43^{\circ} 48^{\prime} 971^{\prime \prime} \mathrm{N}, 3^{\circ} 45^{\prime} 392^{\prime \prime} \mathrm{E}$ & 1.02 & $.01^{\mathrm{ns}}$ & 93 \\
\hline 4/3 Ceyrac & 160 & $43^{\circ} 55^{\prime} 281^{\prime \prime} \mathrm{N}, 3^{\circ} 53^{\prime} 375^{\prime \prime} \mathrm{E}$ & 1.00 & $0^{\text {ns }}$ & 208 \\
\hline 4/4 La Jasse & 250 & $43^{\circ} 46^{\prime} 658^{\prime \prime} \mathrm{N}, 3^{\circ} 46^{\prime} 577^{\prime \prime} \mathrm{E}$ & 1.03 & $.08^{\mathrm{ns}}$ & 323 \\
\hline 4/5 Aeroport & 180 & $43^{\circ} 48^{\prime} 096^{\prime \prime} \mathrm{N}, 3^{\circ} 46^{\prime} 729^{\prime \prime} \mathrm{E}$ & 1.00 & $0^{\mathrm{ns}}$ & 114 \\
\hline 4/6 Pompignan & 190 & $43^{\circ} 53^{\prime} 817^{\prime \prime} \mathrm{N}, 3^{\circ} 50^{\prime} 109^{\prime \prime} \mathrm{E}$ & 1.21 & $2.79^{\mathrm{ns}}$ & 174 \\
\hline 5/1 Le Cros & 730 & $43^{\circ} 52^{\prime} 533^{\prime \prime} \mathrm{N}, 3^{\circ} 22^{\prime} 318^{\prime \prime} \mathrm{E}$ & .93 & $.19^{\text {ns }}$ & 336 \\
\hline 5/2 Le Tibelet & 710 & $43^{\circ} 54^{\prime} 707^{\prime \prime} \mathrm{N}, 3^{\circ} 28^{\prime} 868^{\prime \prime} \mathrm{E}$ & 1.16 & $1.12^{\mathrm{ns}}$ & 201 \\
\hline 5/3 Montdardier & 620 & $43^{\circ} 55^{\prime} 371^{\prime \prime} \mathrm{N}, 3^{\circ} 35^{\prime} 162^{\prime \prime} \mathrm{E}$ & 1.00 & $0^{\mathrm{ns}}$ & 116 \\
\hline 5/4 Rogues & 555 & $43^{\circ} 53^{\prime} 082^{\prime \prime} \mathrm{N}, 3^{\circ} 33^{\prime} 536^{\prime \prime} \mathrm{E}$ & .92 & $.26^{\mathrm{ns}}$ & 140 \\
\hline 5/5 St-Maurice-de-Navacelles & 580 & $43^{\circ} 50^{\prime} 482^{\prime \prime} \mathrm{N}, 3^{\circ} 30^{\prime} 061^{\prime \prime} \mathrm{E}$ & 1.06 & $.16^{\mathrm{ns}}$ & 161 \\
\hline 5/6 St-Pierre-de-la-Fage & 630 & $43^{\circ} 47^{\prime} 820^{\prime \prime} \mathrm{N}, 3^{\circ} 25^{\prime} 315^{\prime \prime} \mathrm{E}$ & .91 & $.28^{\mathrm{ns}}$ & 130 \\
\hline
\end{tabular}

Note. Morph ratio is expressed in terms of the ratio of L-morph plants: S-morph plants. ns $=$ nonsignificant.

"P $P<0.05$ (adjusted threshold $G$ value of 3.814 ).

plots, is the same for all plots and thus the treatments are subject to the same surrounding environment.

For each treatment we distinguished between pollen donors and emasculated S-morph recipient flowers. The two treatments were (1) L-morph donor plants with their upper anthers removed and (2) S-morph donor plants with their upper anthers removed. In both treatments, fully emasculated S-morph plants were used as pollen recipients. Flowers were emasculated before anther dehiscence, in order to prevent any self-fertilization. Emasculation may have reduced visitation by solitary Anthophora bees we have seen visiting flowers at this site but will not reduce visitation by the two Lepidoptera that visit flowers for nectar and are by far the most common visitors to flowers of this species in our study site and elsewhere in the region: the butterfly Gonepteryx cleopatra and the hawkmoth Macroglossum stellatarum. Treatments were randomly allocated to plots before any emasculation.

From March 16 to March 28, 2002, we visited all plots every morning or every $2 \mathrm{~d}$ (if poor weather or no observed buds) before 10 a.m. in order to maintain the treatments in their required condition of donor and recipient flowers before daily pollinator activity. Each morning, newly opened flowers were either randomly emasculated to be recipient or donor flowers or removed by clipping the stem at its base in order to keep a ratio of twice as many donor flowers as recipient flowers. All experimental flowers $(N=674$ plants: 251 flowers of the L-morph as pollen donors, 203 flowers of the S-morph as pollen donors, and 220 flowers of the S-morph as recipients) were marked at the base of the stem with sticky tape to identify donors and recipients and to check for newly opened flowers. The mean number of flowers left in each plot was 24 (range, 6-42) in the S-morph donor plots and 29 (range, 12-54) in the L-morph donor plots. As a result of floral and fruit predation, damaged recipient flowers and fruits (floral and fruit predation) were excluded from analyses. In mid-April we visited the site to record fruit set and damage by herbivory. All predated flowers and fruits were excluded from the analysis. On May 15 we checked all marked stems of plants in the experimental plots and counted fruits and the number of mature seeds and unfertilized ovules in each fruit to assess fruit per flower ratio and, for plants that produced a fruit, seed per ovule ratio on S-morph recipients. Analyses were performed using generalized linear models (PROC GENMOD) with a binomial error distribution in SAS (2009) on fruit per flower and seed per ovule ratios on the full data set with replicate plots nested within treatments. 


\section{Floral Morphology}

During spring 2003, we sampled 30 populations of N. assoanus (fig. 1; table 1) across its geographic range from southern Spain to northern Spain and southern France to quantify morph ratio and population-level variation in floral traits and, in particular, whether anther height variation in the two morphs is related to morph ratio variation among populations. In each population, we obtained a random sample of flowering stems and classified them according to floral morph (for a total of 1676 flowers). The populations were sampled in order to cover the different parts of the species' geographic range in southern and northern Spain and in southern France and to sample populations with biased and nonbiased morph ratios in southern France. Populations in southern France occur in two ecological contexts: on upland limestone plateaus $>600 \mathrm{~m}$ altitude where all known populations have a morph ratio that does not significantly differ from 1:1 or in lowland garrigues $<300 \mathrm{~m}$ where most populations have significantly L-morph-biased morph ratio and a morph ratio that does not significantly differ from $1: 1$. For the purpose of our analyses we thus distinguish different groups of populations in southern France: upland/1:1 morph ratio (group 5), lowland/1:1 morph ratio (group 4), and lowland/L-morph-biased morph ratio (group 3) populations. Populations in Spain were grouped according to their geographic location (group 2 in the north and group 1 in the south) since in the south of Spain a distinct variety, N. assoanus var. praelongus, has been reported. These five groups (fig. 2) thus allow us to test for variation among populations in a robust nested analysis. With the exception of groups 3 and 4, groups are spatially separated from one another by clear-cut geographic or altitudinal variation.

For floral measurements (all taken from fresh flowers), corolla tubes were slit longitudinally from just above the inferior ovary to the mouth. The apex of the ovary was the baseline for all measurements, made with digital callipers to the nearest $0.1 \mathrm{~mm}$. Measurements were made for several floral traits (see fig. 2): floral tube length, style length, and top and bottom of upper and lower anthers. Anther position on the corolla tube was calculated as top anther height - (anther length/2). These data were used to calculate the mean separation of stigma position and anther position between morphs at the population level in two ways: (i) the distance between the mean stigma height of the S-morph and the mean midheight of the lower anthers of the L-morph for each population and (ii) the distance between the mean midheight of the upper anthers of the S-morph and the mean stigma height of the L-morph for each population.

To analyze relationships between morph ratio and floral measurements, we performed ANOVA on floral traits among populations and geographic groups using PROC GLM and correlation analysis using PROC CORR in SAS (2009) to test for correlated variation in mean trait values and population morph ratios. Floral tube length may vary across populations and is often correlated with anther height. So, although previous work has showed no variation among morphs in floral tube length, we controlled for any correlated

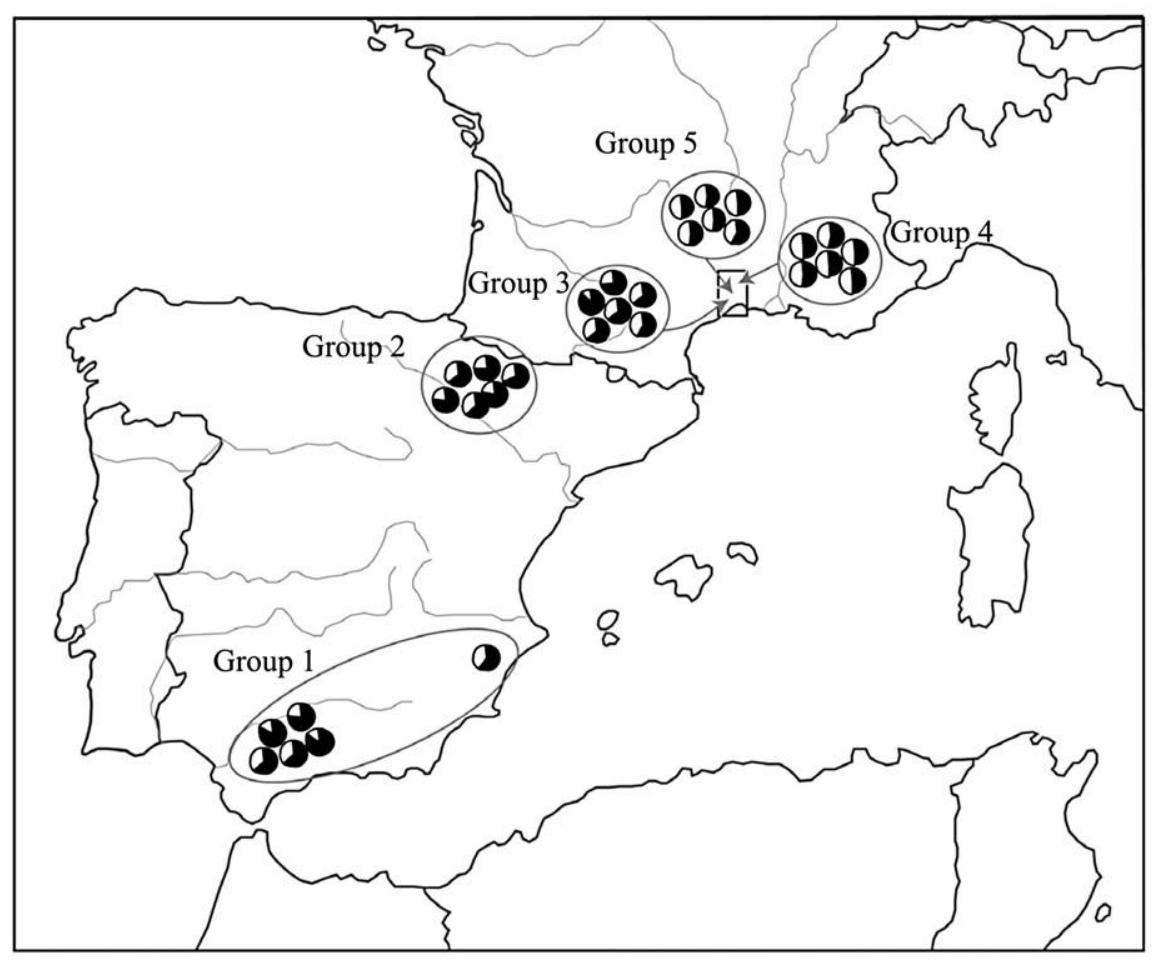

Fig. 2 Geographical location of the 30 populations of Narcissus assoanus and the proportion of L-morph (black) and S-morph (white) individuals in each population. 
variation in anther height by calculating (following our previous work; Baker et al. 2000b) an adjusted upper and lower anther height for each morph as anther position $-b$ (floral tube length - mean floral tube length), where $b$ represents the slope of the line of organ position plotted against floral tube length. This adjustment accounts for variation in anther position caused by variation in floral tube length among individuals but does not significantly alter the value of mean organ position. Differences in adjusted organ position among populations were then assessed using ANOVA with group and population (nested within group) and style morph as main effects.

\section{Results}

\section{Pollen Transfer Efficiency in Experimental Plots}

S-morph plants set significantly more seeds with partially emasculated L-morph pollen donors than with partially emasculated S-morph pollen donors (fig. 3). Although fruit set per flower did not vary significantly among treatments $\left(G_{1}=0.01\right.$, $P>0.90)$ or among plots within each treatment $\left(G_{12}=16.01\right.$, $P>0.10)$, the number of seeds per ovule significantly differed between treatments $\left(G_{1}=106.51, P<0.0001\right)$ and among plots within treatments $\left(G_{24}=300.20, P<0.0001\right)$. S-morph plants set $50 \%$ more seeds with L-morph donors than with S-morph donors. Plots showed no statistical differences in numbers of flowers (after removal of damaged flowers or fruits) between treatments (ANOVA, $F_{1,21}=1.11, P>0.3$; PROC GLM, SAS [2009]) with a mean $( \pm$ SE) of $18.5 \pm 1.6$ pollen donors and $9.25 \pm 0.8$ pollen recipients per plot.

\section{Floral Morphology}

Two-way ANOVA on overall patterns of variation in floral tube length, style length, and adjusted anther height (table 2) confirmed differences in anther placement in the two floral morphs that are clearly more important for lower anther height than upper anther height (witness the 10-fold increase in $F$ ratio for lower anther height differences between the two morphs). The significant interaction between morphs and groups of populations suggests that variation in floral traits is not the same in each floral morph and that biased and unbiased populations show morph-specific patterns of variation (table 2; see fig. 4 for mean population values). ANOVA conducted on each floral morph showed significant variation in adjusted lower anther height among groups, which showed a significant contrast between L-morph-biased populations and 1:1 populations for both morphs (table 3 ). For style length, only the L-morph showed variation among groups, with a significant contrast between groups with biased and unbiased morph ratios.

Visual inspection of differences among populations and groups (fig. 4) provides insights into the nature of the group by morph interactions. First, in populations in southern Spain (group 1), which have a markedly high ratio of Lmorph plants, the lower anthers of the L-morph are placed at a higher level more similar to their position in the Smorph, causing reduced reciprocity with the stigma of the (a)

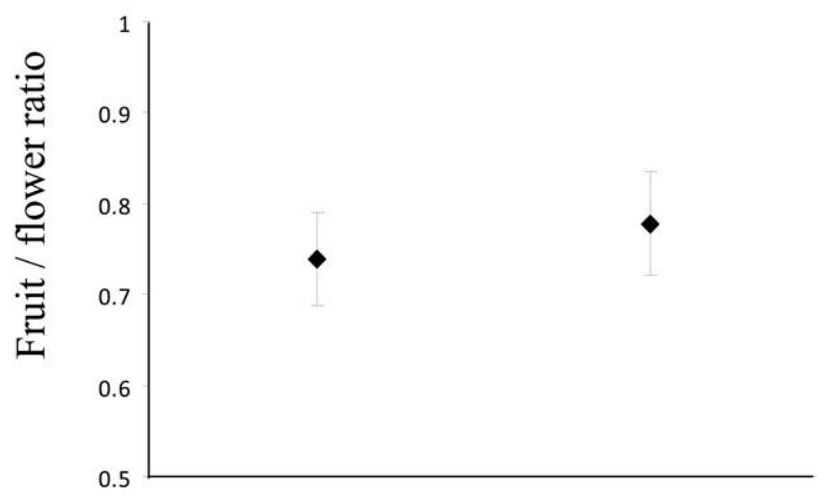

(b)

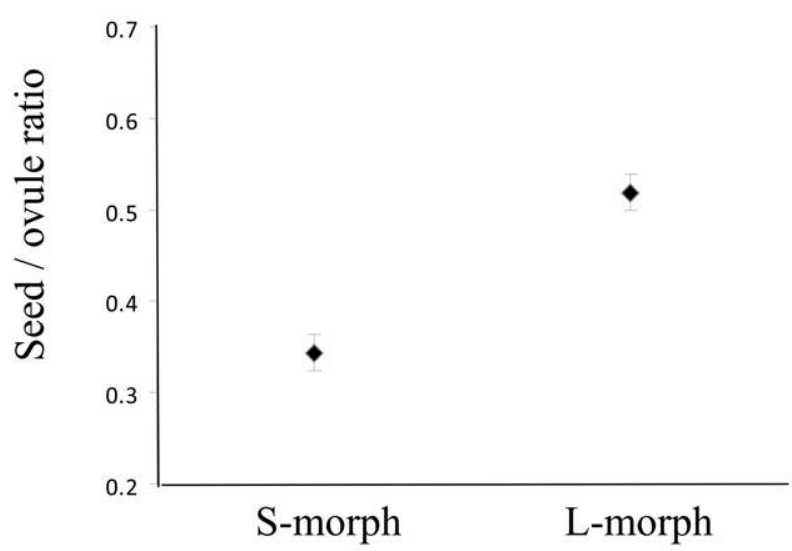

Donor morph treatment

Fig. 3 Influence of pollen morph donor treatment on $(a)$ mean $( \pm \mathrm{SE})$ proportion of flowers setting fruit and $(b)$ mean $( \pm \mathrm{SE})$ proportion of ovules setting seed per fruit by S-morph maternal plants in two experimental donor morph treatments.

S-morph. Second, style length of the L-morph is shorter and more clearly positioned between the midpoint of each of the two anther levels in the upland populations in southern France (group 5). The latter all have a 1:1 morph ratio.

We observed a significant positive correlation (based on a corrected $P$ value to account for multiple [four] comparisons $[P=0.05 / 4=0.0125])$ between morph ratio in a population (ratio of L-morph plants to S-morph plants) and adjusted mean lower and upper anther height in the L-morph and adjusted mean lower and mean upper anther height in the S-morph (table 4). In terms of reciprocity, there was no significant correlation between morph ratio and the distance between stigma height of the L-morph and upper anther height of the S-morph, but we detected a significant correlation between morph ratio and the distance 
Table 2

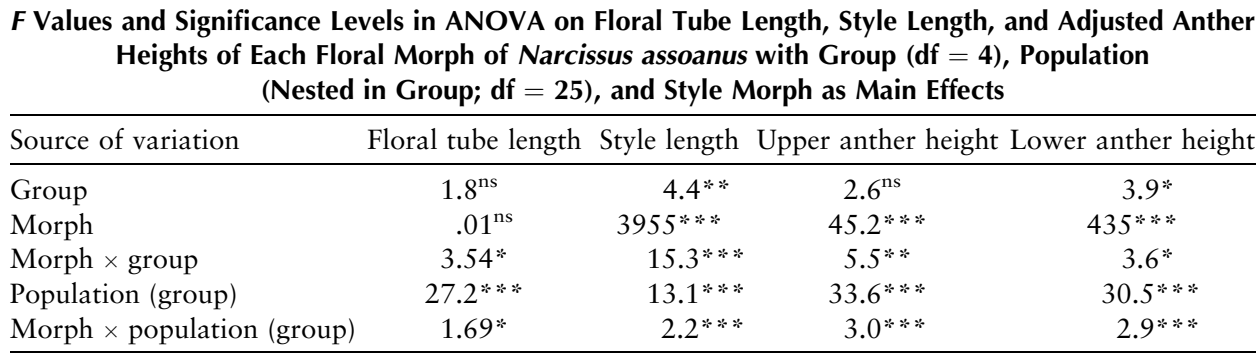

Note. ns $=$ nonsignificant.

"P $<0.05$.

$* * P<0.01$

$* * P<0.001$.

between mean S-morph stigma height and L-morph lower anther height (table 4).

\section{Discussion}

In this study we report how significant variation in female reproductive success and morph ratio variation are both correlated with subtle variation in floral trait positions that affect the reciprocity of stigma and anther position in morphs of the style-dimorphic plant Narcissus assoanus. Although simple correlations are not proof of directional cause-consequence relationships, our joint finding of morphological (correlated variation in morph ratio, lower anther height and reciprocity) and functional differences (effects on seed set) provides evidence for close associations between traits, morph frequency, and fitness variation.

First, our experimental manipulation of plants in a natural population shows how improved reciprocity of S-morph stigmas with the lower-anther level of pollen donors increases their female fitness and the male fitness of the donor morph. S-morph maternal plants set more seed in the presence of Lmorph pollen donors than in the presence of S-morph pollen donors that bear only their lower-level anthers. This result provides a causal explanation for two previous results obtained at the same site for the study species: first, the frequency-dependent increase in seed production by the $S$ morph when rare, i.e., in experimental plots with a $2: 1$ L-morph:S-morph ratio compared to its seed set in plots with 1:1 morph ratio (Thompson et al. 2003), and, second, the finding that the most efficient of the four possible withinand between-morph pollination transfers is from L-morph donors to S-morph receivers (Cesaro and Thompson 2004). In this new study we show how this efficiency may be caused by high reciprocity between the height of the S-morph stigma and the lower anthers of the L-morph. In Cesaro and Thompson (2004), with L-morph donors (with both anthers) fruit set of the S-morph was 0.89 and seed: ovule ratio 0.51 . In our study using L-morph donors with only lower anthers, fruit set of the S-morph was 0.78 and seed set 0.52 . There was thus only a $12 \%$ decline in fruit set associated with the absence of the upper anthers in the L-morph and no decline in seed set on flowers with a fruit, compared to our previous study. The comparison of the two studies thus indicates that the upper anthers of the L-morph make only a small contribution to the pollination of the S-morph and that the major part of pollination of the S-morph in the study population is due to transfer of pollen from the lower anther of the L-morph. We thus provide new evidence for selection on the lower anther level in the L-morph to favor reciprocity with the $\mathrm{S}$-morph stigma in 1:1 populations.

The fitness advantage we detected is thus in relation to a subtle difference in lower anther levels of the two floral morphs of $N$. assoanus and could provide a basis for selection on this floral trait. Strong selection on traits governing male fitness is well known to occur (Stanton et al. 1986; Devlin and Ellstrand 1990; Snow and Lewis 1993) and has recently been demonstrated in a style-polymorphic species, tristylous Narcissus triandrus (Hodgins and Barrett 2008a).

\section{Table 3}

$F$ Values and Significance Levels in Hierarchical ANOVA on Floral Tube Length, Style Length, and Adjusted Anther Heights of Each

Floral Morph of Narcissus assoanus with Group $(\mathrm{df}=4)$ and Population (Nested in Group; $\mathbf{d f}=25$ ) as Main Effects

\begin{tabular}{llcc}
\hline & \multicolumn{3}{c}{ Source of variation } \\
\cline { 2 - 4 } Floral trait and morph & Group & Population & Contrast \\
\hline Floral tube length: & $1.9^{\text {ns }}$ & $42.0^{* * *}$ & $\ldots$ \\
$\quad$ L-morph & $1.6^{\mathrm{ns}}$ & $16.8^{* * *}$ & $\ldots$ \\
$\quad$ S-morph & & & \\
Style length: & $6.35^{* *}$ & $22.7^{* * *}$ & $216.3^{* * * *}$ \\
$\quad$ L-morph & $1.8^{\text {ns }}$ & $13.3^{* * *}$ & $\ldots$ \\
$\quad$ S-morph & & & \\
Upper anther height: & $2.5^{\mathrm{ns}}$ & $90.1^{* * *}$ & $\ldots$ \\
$\quad$ L-morph & $2.6^{\mathrm{ns}}$ & $33.5^{* * *}$ & $\ldots$ \\
$\quad$ S-morph & & & \\
Lower anther height: & $3.3^{*}$ & $79.7^{* * *}$ & $227.9^{* * * *}$ \\
$\quad$ L-morph \\
$\quad$ S-morph
\end{tabular}

Note. If a significant effect due to group was detected in ANOVA, a priori contrasts among biased (groups 1-3) and nonbiased (groups 4 and 5) populations were performed. ns = nonsignificant.

$* P<0.05$.

$* * P<0.01$.

$* * P<0.001$. 
(a)

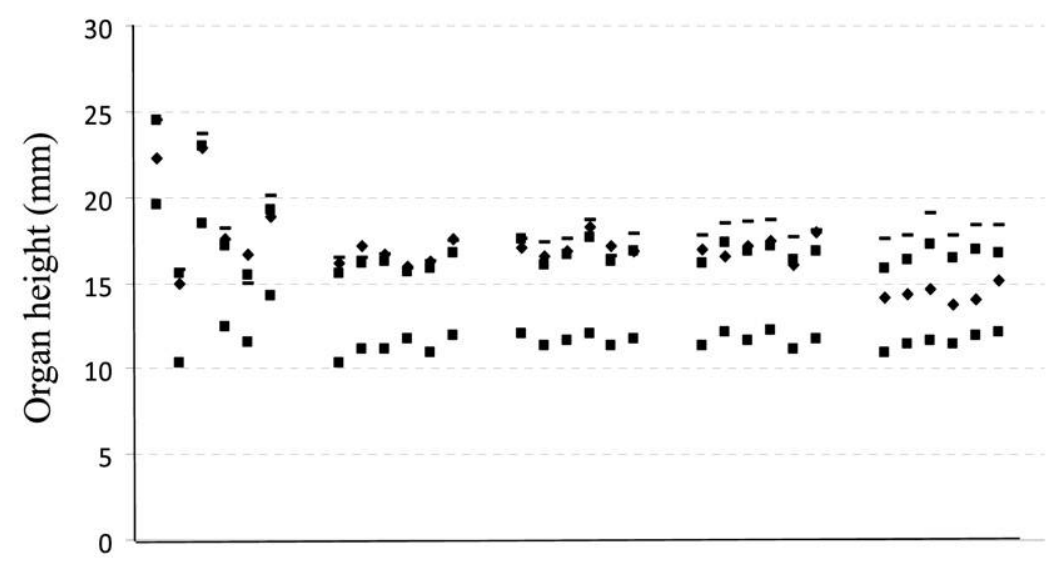

(b)

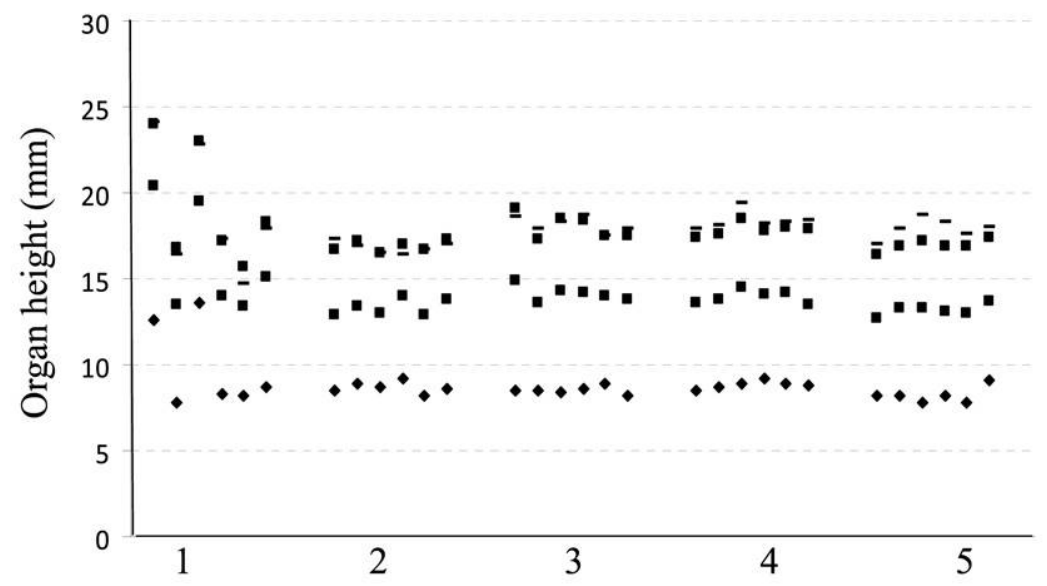

\section{Population group}

Fig. 4 Mean position of sex organs in flowers of $(a)$ the L-morph plant and (b) the S-morph plant of Narcissus assoanus in each of 30 populations (six populations in each of the five geographic groups; fig. 2) across its distribution range. Squares represent mean lower and upper anther heights, diamonds represent mean stigma height, and dashes represents mean length of the floral tube.

Our experimental study provides a particularly revealing demonstration that such selection can occur in a natural population where natural pollinators are operating and thus its possible role in the dynamics of a floral polymorphism.

Narcissus assoanus pollination in southern France is primarily by one species of butterfly (Gonepteryx cleopatra) and hawkmoth (Macroglossum stellatarum) and less often by other Lepidoptera, solitary bees in the genus Anthophora, or, rarely, bumblebees (Baker et al. 2000a; J. D. Thompson and R. Berjano, unpublished observations). The major pollinators are thus long-tonged Lepidoptera that feed on nectar at the base of the corolla tube and can thus exert the selection pressure for the reciprocity of lower-level anthers on the L-morph with the stigma of the S-morph. This selective pressure to increase the efficiency of pollen transfer (Lloyd and Webb 1992a, 1992b) can be a force promoting the evolution of anther height in a stigmaheight-dimorphic species toward distyly. However, no populations of $N$. assoanus show complete reciprocity for low-level sex organs. In this species, disassortative (intermorph) pollination creates conditions for the stability of the stigma-height dimorphism and the assortative pollination, which, when it occurs, does not engender pollen wastage due to lack of heteromorphic incompatibility. Hence, there will be only low levels of selection for complete reciprocity, i.e., an evolution to complete distyly (Lloyd and Webb 1992a, 1992b; Barrett et al. 2004). Indeed, weak selection on anther height that leads to complete reciprocity and heterostyly seems to be a general picture in the genus, as only one species in this multispecies group shows distyly 


\section{Table 4}

Pearson Correlation Coefficients between Morph Ratio and Anther Heights and Reciprocity across Populations of Narcissus assoanus

\begin{tabular}{lcc}
\hline Adjusted mean anther height and morph & $r$ & Significance $(P)$ \\
\hline Lower anthers: & & \\
$\quad$ L-morph & .488 & $<.0125$ \\
S-morph & .479 & $<.0125$ \\
Upper anthers: & & \\
$\quad$ L-morph & .458 & $<.0125$ \\
$\quad$ S-morph & .475 & $<.0125$ \\
Reciprocity: & & \\
$\quad$ L-morph & .309 & $>.05$ \\
S-morph & .401 & $<.05$ \\
\hline
\end{tabular}

Note. L-morph: distance between stigma height of the L-morph and upper anther height of the S-morph; S-morph: distance between mean S-morph stigma height and L-morph lower anther height.

(Narcissus albimarginatus), whereas several species show a stigma-height dimorphism (Barrett and Harder 2005).

The second result of our study concerns the variation in floral traits and its relationship with morph ratio variation. In populations in southern Spain (group 1), all of which have a high ratio of L-morph plants, the lower anthers of the Lmorph are, on average, placed at a higher level more similar to their position in the S-morph, causing reduced reciprocity with the stigma of the S-morph. For the populations in southern Spain there are also high levels of among-population variation in lower anther position in the L-morph. In the other groups, the lower anthers of the L-morph are placed consistently lower in the flower. The greatly reduced reciprocity in populations in southern Spain, where the floral phenotype appears to be very different in terms of both overall floral size (corolla tube length) and the positioning of floral traits, is a primary cause of the significant correlation between morph ratio and the distance between mean S-morph stigma height and L-morph lower anther height. A variant of the species-N. assoanus var praelongus - has been described in southern Spain, and its precise geographic delimitation and association with variation in functional floral traits now require investigation. Our results indicate that this variant may have a different floral phenotype and may represent a distinct phylogentic lineage that has evolved independently of other populations of $N$. assoanus elsewhere in its range.

In tristylous Narcissus triandrus in the Iberian Peninsula, geographic variation in morph frequencies is associated with significant variation in flower size, causing changes in the reciprocity of anther and stigma heights in a way that predicts morph frequency (Barrett et al. 2004; Hodgins and Barrett 2008b). In this species, variation in female fertility can contribute to morph ratio changes, particularly when the strength of frequency-dependent selection varies among the morphs because of asymmetrical mating patterns. Hodgins and Barrett (2006) provide evidence for a female fertility dis- advantage that may play a role in the decline in frequency and loss from populations of the midstyle morph (M-morph). In the three populations with the lowest M-morph frequency, the M-morph had significantly lower proportional seed set than the other two morphs, probably because of low reciprocity of its stigma with anthers in the other morphs (Barrett et al. 2004). Our study thus follows others that provide evidence of relationships between trait variation and morph ratio variation in floral polymorphic species.

In our study the variation in lower anther height of the Lmorph is primarily due to a geographic distinction between populations in southern Spain and those elsewhere in the range of N. assoanus. As a result, in southern France where some populations have a $1: 1$ ratio and others an L-morphbiased ratio, there is little difference in the position of the lower anther of the L-morph in the floral tube. The correlation is thus apparent across geographic regions but not within the region where $1: 1$ populations have been reported. In this region, it has been suggested that colonization events or fragmentation of populations may contribute to the deviation of morph ratios from $1: 1$ as a result of stochastic loss of the dominant gene for short styles (Thompson 2005). Indeed, previous (Baker et al. 2000b, 2000c) and current (R. Berjano, unpublished data) work on $N$. assoanus indicates that, in southern France, the spatial extent of populations is closely correlated with morph ratio variation. Basically, spatially extensive populations (often connected to each other across the landscape) consistently have isoplethic morph ratios, whereas spatially small or isolated and fragmented populations have morph ratios that vary from highly Lmorph-biased ratios to occasionally isoplethic ratios. Population fragmentation and turnover may thus cause morph ratio variation and the lack of any trait variation between isoplethic and L-morph-biased populations.

In conclusion, the evidence that subtle variation in anther height involving increased reciprocity of lower-level anthers of the L-morph with stigmas of the S-morph enhances female fertility of the latter in the stigma-height-dimorphic N. asoanus provides new evidence for natural selection on a functional floral trait. In addition, correlated variation in morph ratio and the same floral trait across the geographic range of the species opens an interesting perspective in terms of potentially different evolutionary forces acting in the different parts of the range of this species.

\section{Acknowledgments}

This work was financed by grants from the Spanish Ministry for Science and Technology (CGL2006-13847-CO2, CGL200912565) and a PhD fellowship from the French government to A. C. Cesaro. We thank Jean-Baptiste André, Daniel Gomez, Justin Amiot, and Rocío Pérez-Barrales for practical help in the field.

\section{Literature Cited}

$\rightarrow$ Arroyo J, SCH Barrett, R Hidalgo, WW Cole 2002 Evolutionary maintenance of stigma-height dimorphism in Narcissus papyraceus (Amaryllidaceae). Am J Bot 89:1242-1249.
Arroyo J, A Dafni 1995 Variations in habitat, season, flower traits and pollinators in dimorphic Narcissus tazetta L. (Amaryllidaceae) in Israel. New Phytol 129:135-145. 
$\rightarrow$ Baker AM, SCH Barrett, JD Thompson 2000a Variation of pollen limitation in the early flowering Mediterranean geophyte Narcissus assoanus (Amaryllidaceae). Oecologia 124:529-535.

$\rightarrow$ Baker AM, JD Thompson, SCH Barrett 2000b Evolution and maintenance of stigma-height dimorphism in Narcissus. I. Floral variation and style-morph ratios. Heredity 84:502-513.

$\rightarrow-2000 c$ Evolution and maintenance of stigma-height dimorphism in Narcissus. II. Fitness comparisons between style morphs. Heredity 84:514-524.

$\rightarrow$ Barrett SCH, LD Harder 2005 The evolution of polymorphic sexual systems in daffodils (Narcissus). New Phytol 165:45-53.

Barrett SCH, LD Harder, WW Cole 2004 Correlated evolution of floral morphology and mating-type frequencies in a sexually polymorphic plant. Evolution 58:964-975.

Barrett SCH, DG Lloyd, J Arroyo 1996 Stylar polymorphisms and the evolution of heterostyly in Narcissus (Amaryllidaceae). Pages 339-376 in DG Lloyd, SCH Barrett, eds. Floral biology: studies on floral evolution in animal-pollinated plants. Chapman \& Hall, New York.

$\rightarrow$ Cesaro AC, SCH Barrett, S Maurice, B Vaissière, JD Thompson 2004 An experimental evaluation of self-interference in Narcissus assoanus: functional and evolutionary implications. J Evol Biol 17:1367-1376.

$\rightarrow$ Cesaro AC, JD Thompson 2004 Darwin's cross-promotion hypothesis and the evolution of stylar polymorphism. Ecol Lett 7:1209-1215.

$\rightarrow$ Curtis J, CF Curtis 1985 Homostyle primroses re-visited. I. Variation in time and space. Heredity 54:227-234.

$\rightarrow$ Devlin B, NC Ellstrand 1990 Male and female fertility variation in wild radish, a hermaphrodite. Am Nat 136:87-107.

$\rightarrow$ Eckert CG, D Manicacci, SCH Barrett 1996 Frequency-dependent selection on morph ratios in tristylous Lythrum salicaria (Lythraceae). Heredity 77:581-588.

Fisher RA 1930 The genetical theory of natural selection. Dover, New York.

$\rightarrow$ Gigord LDB, MR Macnair, A Smithson 2001 Negative frequency dependent selection maintains a dramatic flower color polymor- phism in the rewardless orchid Dactylorhiza sambucina (L.) Soo. Proc Natl Acad Sci 98:6253-6255.

Hodgins KA, SCH Barrett 2006 Female reproductive success and the evolution of mating-type frequencies in tristylous populations. New Phytol 171:569-580.

$\rightarrow-2008 a$ Geographical variation and style-morph ratios in a sexually polymorphic daffodil. Am J Bot 95:185-195.

$\rightarrow-2008 b$ Natural selection on floral traits through male and female function in wild populations of the heterostylous daffodil Narcissus triandrus. Evolution 62:1751-1763.

Lloyd DG, CJ Webb 1992a The evolution of heterostyly. Pages 151178 in SCH Barrett, ed. Evolution and function of heterostyly. Springer, Berlin.

- 1992b The selection of heterostyly. Pages 179-207 in SCH Barrett, ed. Evolution and function of heterostyly. Springer, Berlin.

$\rightarrow$ McCauley DE, MT Brock 1998 Frequency-dependent fitness in Silene vulgaris, a gynodioecious plant. Evolution 52:30-36.

$\rightarrow$ Pérez-Barrales R, J Arroyo 2010 Pollinator shifts and the loss of style polymorphism in Narcissus papyraceus (Amaryllidaceae). J Evol Biol 23:1117-1128.

$\rightarrow$ Pérez-Barrrales R, P Vargas, J Arroyo 2006 New evidence for the Darwinian hypothesis of heterstyly: breeding systems and pollinators in Narcissus sect. Apodanthi. New Phytol 171:553-567.

SAS 2009 SAS/STAT user's guide. SAS, Cary, NC.

$\rightarrow$ Snow AA, PO Lewis 1993 Reproductive traits and male fertility in plants: empirical approaches. Annu Rev Ecol Syst 24:331-351.

$\rightarrow$ Stanton ML, AA Snow, SN Handel 1986 Floral evolution: attractiveness to pollinators influences male fitness. Science 232:16251627.

Thompson JD 2005 Plant evolution in the Mediterranean. Oxford University Press, Oxford.

$\rightarrow$ Thompson JD, SCH Barrett, AM Baker 2003 Frequency-dependent variation in reproductive success in Narcissus: implications for the maintenance of stigma-height dimorphism. Proc R Soc B 270: 949-953. 